\title{
Urban effects on the diurnal temperature cycle in Phoenix, Arizona
}

\author{
Bohumil M. Svoma*, Anthony Brazel \\ School of Geographical Sciences and Urban Planning, Arizona State University, Tempe, Arizona 85287, USA
}

\begin{abstract}
Empirical estimations of urban effects on the diurnal temperature cycle were carried out for Phoenix, Arizona, through a framework capable of estimating the mean urban effect on air temperature. The analysis of pre-urban and urban differences in hourly temperature data at Sky Harbor International Airport during dry tropical conditions in June and January revealed a significant urban influence. Minimum temperature was most influenced by urbanization with the mean minimum temperature during the urban period exceeding that of the pre-urban period by $4.4^{\circ} \mathrm{C}\left(2.4^{\circ} \mathrm{C}\right)$ in June (January). A significant urban heat sink in January maximum temperatures was evident as the mean maximum temperature during the pre-urban period exceeded that of the urban period by $1.5^{\circ} \mathrm{C}$. The greater thermal inertia due to urban growth around the airport and the growth of the airport itself has also had an effect on nocturnal cooling rates. Pre-urban January minimum temperatures typically occurred between 06:00 and 07:00 local standard time (LST) in the pre-urban period and between 07:00 and 08:00 LST in the urban period. Similarly, in June, the minimum temperature occurred on average around 05:00 LST during the pre-urban period and between 05:00 and 06:00 LST during the urban period. This apparent decrease in cooling rates was modeled well by the first harmonic fit to the average hourly temperature data.
\end{abstract}

KEY WORDS: Urban climate $\cdot$ Phoenix $\cdot$ Diurnal $\cdot$ Air temperature Resale or republication not permitted without written consent of the publisher

\section{INTRODUCTION}

In past urban climate research, 5 major methods have been utilized to estimate the effects on climate due to urbanization including: (1) contemporaneous urban-rural differences, (2) contemporaneous upwind-downwind differences, (3) contemporaneous urban-regional differences, (4) time trends in these differences and (5) contemporaneous weekday-weekend differences (Lowry 1977). There are certainly shortcomings of these methods which have been documented (Lowry 1977, 1998). In general, these shortcomings are due to the controls that are necessary to account for several influences including (1) the spatial variability of a given weather element independent of urbanization, (2) changing regional climate, (3) synoptic-scale weather patterns and wind direction (for the upwind-downwind methods in particular) and (4) the presence of many other latent variables (weekend-weekday methods in particular). To handle these shortcomings, Lowry (1977) devised a framework to empirically estimate urban effects on climate. The basis of this framework is that the mean urban effect can be accurately measured through examining differences in a variable between pre-urban and urban time periods.

Urban growth and airport development around the first-order weather station located at Sky Harbor International Airport in Phoenix, Arizona, began shortly after 1948 with new infrastructure and a new terminal in 1952. Expansion continued, resulting in 3 more terminals and a large expansion of runways. The annual number of airport passengers increased from 296066 in 1952 to 15.4 million just prior to 1998 (History of Sky Harbor Airport, www.phoenix.gov/skyharborairport/ about-sky-harbor/history.html). In addition, growth of the City of Phoenix surrounding the airport was occurring simultaneously. The resulting urban heat island 
(UHI) in the Phoenix metropolitan area has been studied extensively by previous investigators (Cayan \& Douglas 1984, Balling \& Cerveny 1987, Balling et al. 1990, Brazel et al. 2000, 2007, Hawkins et al. 2004, Fast et al. 2005).

Many previous investigations of the UHI in Phoenix did not apply the model proposed by Lowry (1977). Fast et al. (2005) and Hawkins et al. (2004) focused on the daily maximum UHI through urban and rural differences. Brazel et al. (2000) focused on trends in urban-rural differences in maximum and minimum temperatures for the month of May. Balling et al. (1990) focused on trends in mean, minimum and maximum temperatures at an urban station and Balling \& Cerveny (1987) focused on urban-rural temperature differences for each month from 1948 to 1985. Lastly, Cayan \& Douglas (1984) compared temperature trends at urban and rural sites. Considering the framework outlined by Lowry (1977), the results from all of these studies should not be seen as exact estimations of the true magnitude of the UHI at the urban sites considered because the methods employed require numerous controls to account for the numerous latent variables. These studies are important, however, because the existence and nature of urban effects are presented. The general nature of the Phoenix UHI documented in these studies includes characteristics such as a stronger nocturnal UHI and a daytime urban heat sink (Cayan \& Douglas 1984, Balling et al. 1990, Brazel et al. 2000, Fast et al. 2005).

Research regarding the influence of urbanization on nocturnal cooling rates and the diurnal temperature cycle in Phoenix is fairly limited. Fast et al. (2005) noted a UHI maximum at midnight with a secondary maximum typically occurring 2 to $3 \mathrm{~h}$ after sunrise, but did not investigate the urban influence on nocturnal cooling rates. A decrease in nocturnal cooling rates due to urbanization has been suggested by past researchers due to greater thermal inertia (Kidder \& Essenwanger 1995, Holmer et al. 2007). Kidder \& Essenwanger (1995) found higher cooling rates in a smaller city compared to a larger city and Holmer et al. (2007) found higher cooling rates for less dense urban areas with lower building height.

The goal of the present study was to use the framework described by Lowry (1977) to accurately estimate the mean effects of urbanization on the diurnal temperature cycle in the Phoenix metropolitan area. We focused on dry tropical (DT) synoptic conditions (the hottest and driest conditions relative to the climate of Phoenix) during June and January, and applied the framework to the first-order weather station at Phoenix Sky Harbor International Airport. Considering the past Phoenix UHI research mentioned above and the reduced urban cooling rates suggested by previous researchers (Kidder \& Essenwanger 1995, Holmer et al. 2007), we expected to find a decrease in the amplitude of the diurnal temperature cycle and a shift toward a later occurrence of minimum temperatures due to the urban growth around and expansion of Phoenix Sky Harbor International Airport.

\section{DATA}

Hourly air temperature data for Sky Harbor International Airport were obtained from the National Climatic Data Center extending back to January 1932. A calendar of daily synoptic weather type for Phoenix, Tucson and Yuma, Arizona, was obtained from the spatial synoptic classification developed by Sheridan (2002, http://sheridan.geog.kent.edu/ssc.html). This classification algorithm (SSC2) improves upon the earlier spatial synoptic classification developed by Kalkstein et al. (1996) by considering the synoptic conditions of several stations adjacent to a given station. This results in a higher match percentage in synoptic weather type at adjacent stations (Sheridan 2002). Additionally, the SSC2 provides synoptic weather types not only for the winter and summer seasons, but for each day of the year through the use of sliding seed days (Sheridan 2002).

A seed day is an actual day in which weather conditions at a given location match a given weather type. Seed day thresholds for each weather type and the days that fall within these thresholds were determined for four 2-wk seasons defined by the hottest and coldest time of year for a given station (Sheridan 2002). These thresholds and resulting seed days were determined through the analysis of various weather maps, weather data and local meteorological differences between adjacent stations (Kalkstein et al. 1996, Sheridan 2002). For example, during the hottest part of the year in Phoenix, a dry tropical day has an afternoon temperature greater than $39^{\circ} \mathrm{C}$, afternoon dew point lower than $13^{\circ} \mathrm{C}$, cloud cover between zero and 10 tenths, afternoon dew point depression greater than $28^{\circ} \mathrm{C}$, a minimum temperature between -99 and $99^{\circ} \mathrm{C}$ and a maximum dew point range of $12^{\circ} \mathrm{C}$ (S. Sheridan pers. comm.).

For the four 2-wk seasons, seed day means of 14 weather variables (see Table 1) were calculated for each air mass type. These means were compared to the overall mean of these variables during each $2 \mathrm{wk}$ period. An algorithm based on these differences and the annual curve of the overall means of these weather variables was employed to produce theoretical seed day means of these 14 variables for each weather type for each day of the year (Sheridan 2002). 
Table 1. Average (June and January) theoretical seed day values for the 14 variables used in the creation of the SSC2 calendar in Phoenix, Arizona for dry tropical conditions: temperature $\left(\mathrm{T},{ }^{\circ} \mathrm{C}\right)$ and dew point depression $\left(\mathrm{DD},{ }^{\circ} \mathrm{C}\right)$ at different times $($ local standard time); diurnal temperature range $\left(\mathrm{DTR},{ }^{\circ} \mathrm{C}\right)$; dew point range $\left(\mathrm{DPR},{ }^{\circ} \mathrm{C}\right)$; mean sea level pressure $(\mathrm{SLP}, \mathrm{hPa}) ; \mathrm{mean}$ cloud cover $\left(\mathrm{CC}\right.$, in tenths); pressure range $(\mathrm{PR}, \mathrm{hPa})$; and wind shift $\left(\mathrm{WS}, \mathrm{m} \mathrm{s}^{-1}\right)$

\begin{tabular}{|c|c|c|c|c|c|c|c|c|c|c|c|c|c|c|}
\hline \multirow{2}{*}{ Month } & \multicolumn{2}{|c|}{ 02:00 } & \multicolumn{2}{|c|}{ 08:00 } & \multicolumn{2}{|c|}{$14: 00$} & \multicolumn{2}{|c|}{$20: 00$} & \multirow{2}{*}{ DTR } & \multirow[t]{2}{*}{ DPR } & \multirow[t]{2}{*}{ SLP } & \multirow[t]{2}{*}{$\mathrm{CC}$} & \multirow[t]{2}{*}{ PR } & \multirow[t]{2}{*}{ WS } \\
\hline & $\mathrm{T}$ & $\mathrm{DD}$ & $\mathrm{T}$ & $\mathrm{DD}$ & $\mathrm{T}$ & $\mathrm{DD}$ & $\mathrm{T}$ & $\mathrm{DD}$ & & & & & & \\
\hline June & 29.3 & 24.0 & 31.0 & 25.4 & 41.8 & 38.0 & 38.2 & 34.1 & 12.6 & 4.9 & 1006.8 & 1.5 & 4.6 & 6.3 \\
\hline January & 10.4 & 10.3 & 9.3 & 9.9 & 25.6 & 27.8 & 17.8 & 17.4 & 16.8 & 4.1 & 1017.8 & 2.4 & 4.1 & 4.4 \\
\hline
\end{tabular}

The average January and June theoretical seed day means of these variables for dry tropical conditions in Phoenix are displayed in Table 1 (S. Sheridan pers. comm.).

After the calculation of theoretical seed day means, each day in the period of record at a given station was then assigned an air mass type (Sheridan 2002). The designated air mass type is simply the one that produces the lowest equally weighted sum of squared z-scores based on the observed variable values, the standard deviation of the variable values (for a given day of the year) and the theoretical seed day means of 12 of the 14 variables in Table 1 (excluding diurnal wind shift and sea level pressure range) for that air mass. A similar z-score method was then used to determine which days were more likely transitioning between air mass types. This method, however, is based on only 3 variables (diurnal dew point range, diurnal sea level pressure range, and diurnal wind shift) that typically obtain high values during transition days between air mass types (Sheridan 2002).

Thus the SSC2 calendar classified each day as 1 of 7 air mass types for 327 stations in the US and Canada which largely extend back to 1948. The 7 air mass types include (1) dry polar (DP), (2) dry moderate (DM), (3) dry tropical (DT), (4) moist polar (MP), (5) moist moderate (MM), (6) moist tropical (MT) and (7) transitional (TR). A detailed explanation of these air mass types as well as the development of the SSC2 can be found in Sheridan (2002). A shortcoming of the SSC2 is that local land use effects are not accounted for in the algorithm (Sheridan 2002). This can result in a UHI signal in the SSC2 calendar. Previous investigators have suggested that there is a strong UHI bias in the SSC2 climatology for Phoenix (Kalkstein et al. 1998); however, we controlled for this bias using daily NCEP/NCAR reanalysis $500 \mathrm{hPa}$ geopotential heights from NOAA's Earth Science Research Laboratory (www.cdc.noaa.gov/data/gridded/). These data extend back to 1 January 1948.

Lastly, selected oblique and overhead aerial photos of Sky Harbor Airport were obtained from the archives of the Phoenix Airport Museum for the period 1941 to 2007.

\section{METHODS}

\subsection{Empirical framework}

The model proposed by Lowry (1977) can be written as $M_{i t x}=C_{i t x}+L_{i t x}+E_{i t x}$, where $M$ is a measured weather element at station $x$, under synoptic weather type $i$ during a time period $t$. The variable $C$ represents the value of $M$ in the absence of landscape effects or urban effects. The variable $L$ is the value not accounted for by $C$ that $M$ would have due to only landscape effects. Lastly, $E$ represents the value not accounted for by $C$ that $M$ would have due to only urban effects. The variables $M, C, L$ and $E$ are from distributions with non-zero variances such that $\bar{M}, \bar{C}, \bar{L}$ and $\bar{E}$ are the means of these distributions. Assuming that, for all pairs of time periods $A$ and $B, \bar{C}_{i A x}=\bar{C}_{i B X}$ $\bar{L}_{i A x}=\bar{L}_{i B X}$ and $\bar{E}_{i 0 x}=0$, then $\bar{M}_{i t x}-\bar{M}_{i 0 x}=\bar{E}_{i t x}$ where $t=0$ represents the start of urbanization. This simply states that under the specified assumptions, the true mean UHI effect for certain synoptic conditions can be estimated as the difference in the means between a measured weather variable during an urban and a preurban time period. For further details on this framework, see Lowry (1977).

In accordance with the above model, we defined pre-urban and urban periods for Sky Harbor International Airport. The urban period was defined as 19982007. Admittedly, the pre-urban period (1948-1957) was chosen based on the limitations of our data, as the SSC2 calendar and the reanalysis data only extend back to 1948; however, as seen in Fig. 1, the development around Sky Harbor International Airport was fairly limited at this time as compared to 2005 (Fig. 2). Furthermore, Hansen et al. (1999) found the UHI in Phoenix to only be apparent during the latter half of the 20th century.

\subsection{Synoptic classification}

Another key component of the framework proposed by Lowry (1977) is the identification of synoptic weather types. Recognizing a potential urban bias in 


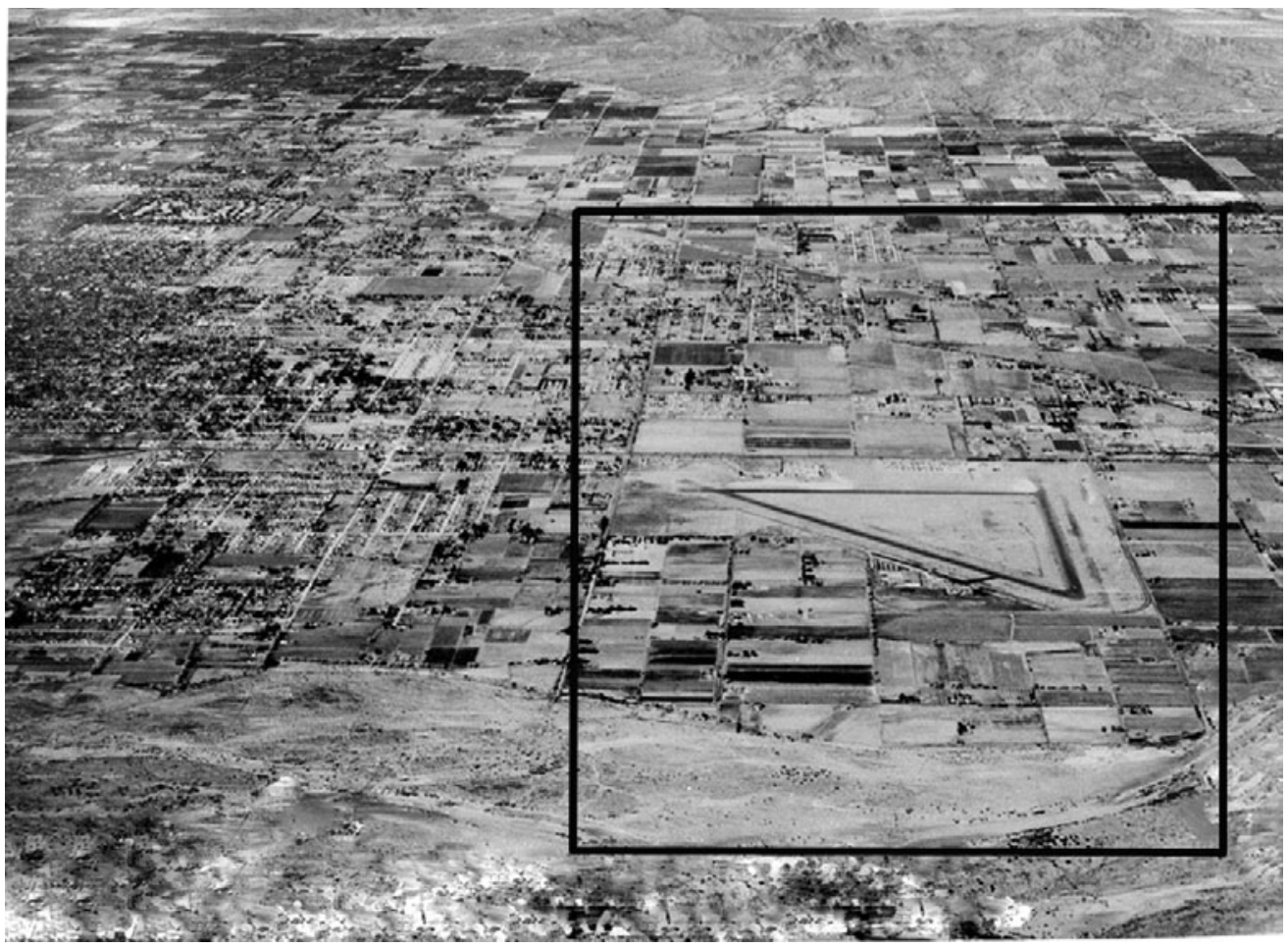

Fig. 1. View of the airport looking north in 1946; Salt River in the foreground. The black outline indicates the approximate area depicted by Fig. 2

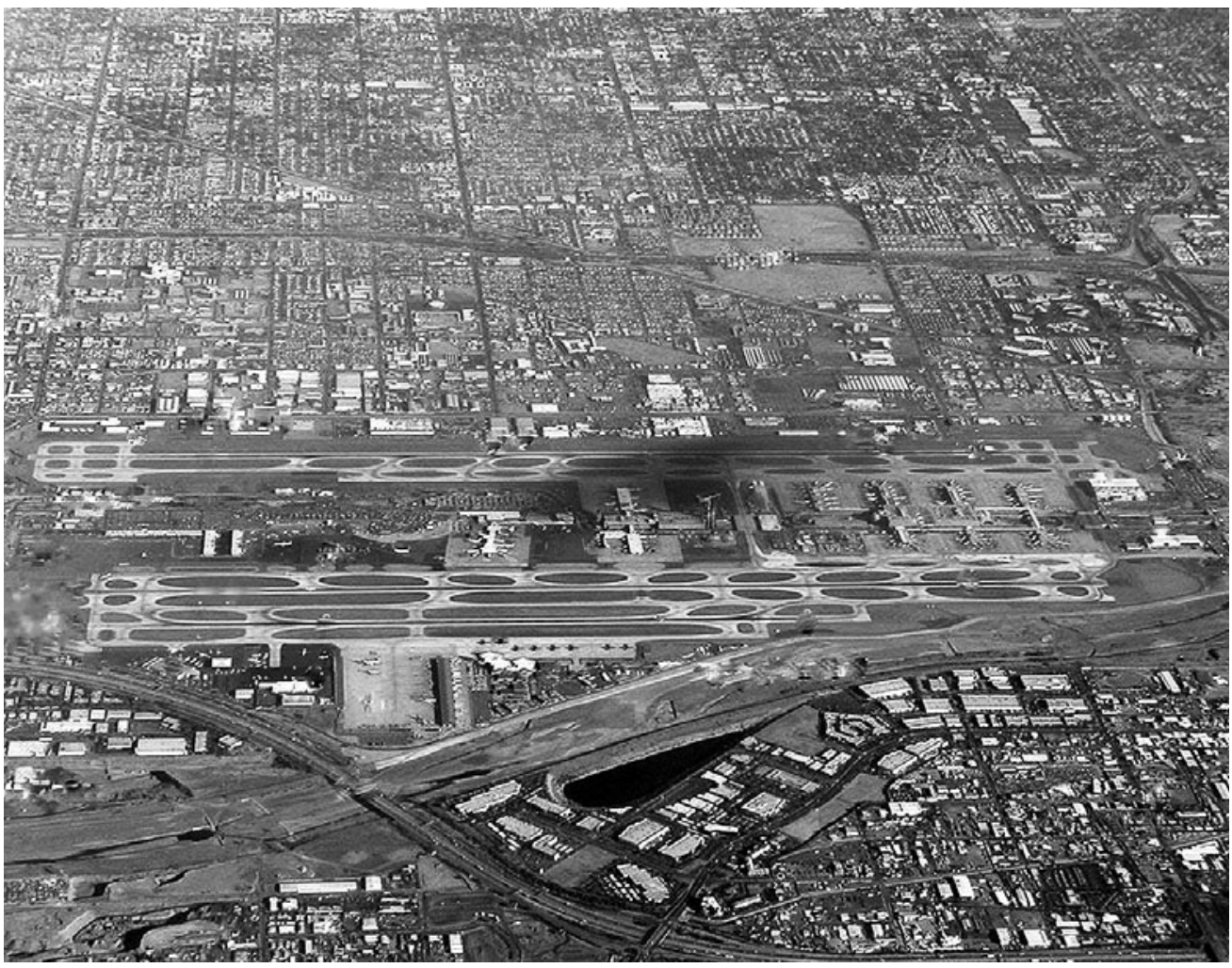

Fig. 2. View of the airport looking north in 2005; Salt River in the foreground 

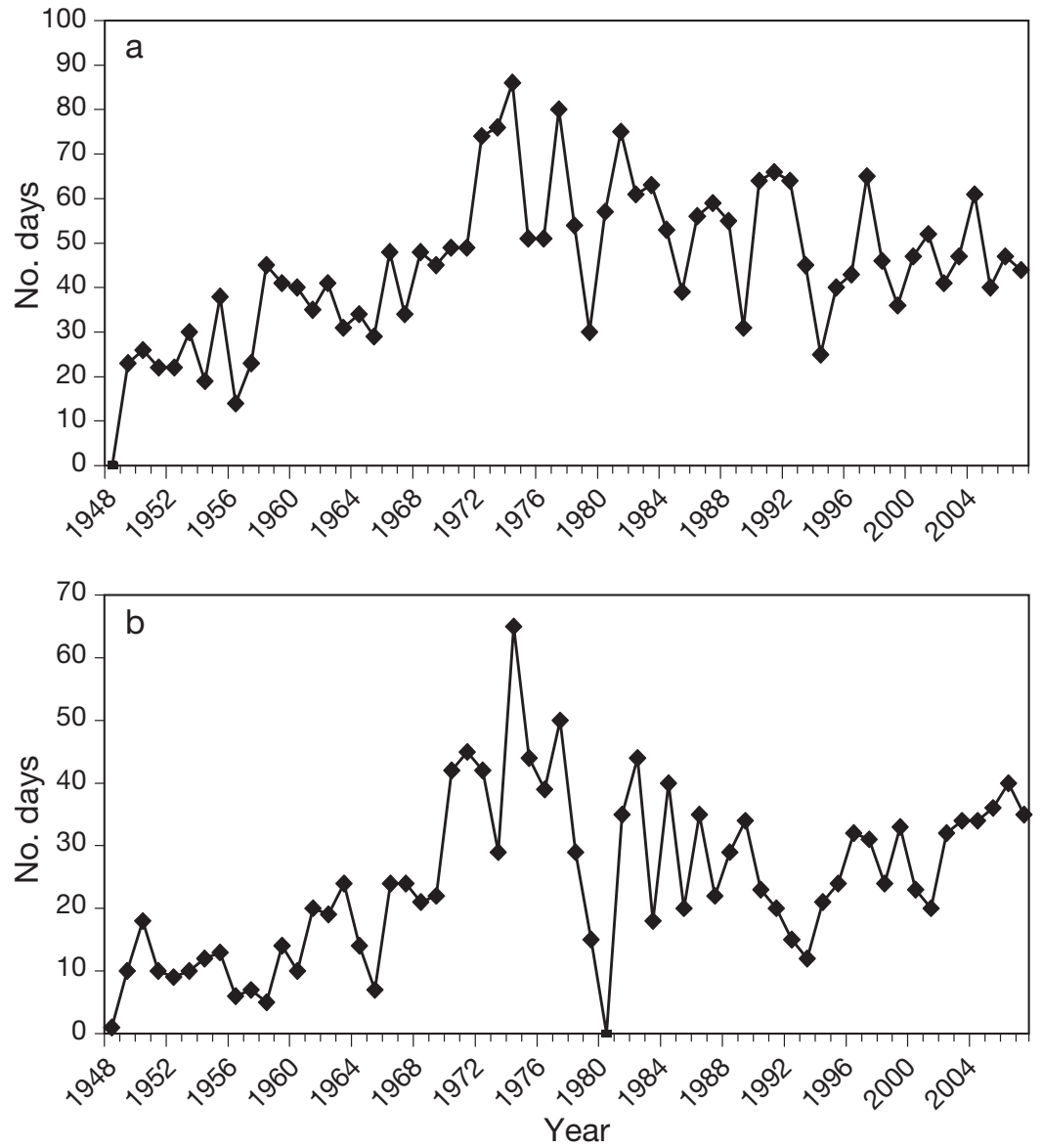

Fig. 3. Annual number of days that Phoenix recorded a hotter SSC2 air mass type than (a) Tucson and (b) Yuma

the Phoenix SSC2 climatology (Kalkstein et al. 1998), we investigated the $500 \mathrm{hPa}$ geopotential heights for DT conditions as well as trends in the SSC2 agreement between Phoenix, Yuma and Tucson, Arizona. Displayed in Fig. 3 are the yearly time series of the number of days in which the SSC2 synoptic type was hotter for Phoenix than Tucson or Yuma. The large increasing trends are indicative of an increasing lack of agreement in the SSC2 between Phoenix and these nearby locations likely due to the growing UHI in Phoenix. For both time series, a peak occurred in 1974 after which the trend appeared to stop (Fig. 3). This is likely due to a decline in the rate of UHI increase detectable at Sky Harbor International Airport. Previous researchers have suggested that as a city expands around a location, more localized urban modifications become limited as the majority of growth is seen near the urban fringes (Brazel et al. 2000). This slows the acceleration of the heat island at that location (Brazel et al. 2000). In particular, no major increase in temperature has been observed at Sky Harbor International Airport since 1990 (Brazel et al. 2007).
As further illustration of the increasing lack of agreement between Phoenix and these adjacent locations, we examined the frequency of DT days during preurban and urban periods. The number of pre-urban DT days for Phoenix, Tucson and Yuma were 1233, 1596 and 1776, respectively. While this number increased to 1888 for Phoenix during the urban period, it only slightly increased to 1651 for Tucson and decreased to 1579 for Yuma. In addition, for June DT days in Phoenix, higher (lower) 500 hPa geopotential heights were present over the western and midwestern US (eastern US) during the pre-urban period as opposed to the urban period (Fig. 4). Two-sample $t$-tests showed that these differences were significant $(p<0.05)$ for many reanalysis grids including the grid nearest to Phoenix $\left(32.5^{\circ} \mathrm{N}, 112.5^{\circ} \mathrm{W}\right)$ where the average (median) pre-urban geopotential height was 5884 (5893) geopotential m and the average urban geopotential height was 5874 (5878) geopotential m. This suggests differing synoptic conditions during Phoenix DT days in June between pre-urban and urban periods with a greater tendency toward ridging (higher $500 \mathrm{hPa}$ geopotential heights) over the western US during the pre-urban period (Fig. 4). This signal is likely in response to the urban effect on the SSC2 present in Phoenix during recent years (Kalkstein et al. 1998).

Considering the differing synoptic conditions between pre-urban and urban periods for DT days in Phoenix discussed above, we could not use the SSC2 alone to stratify our temperature data. Therefore, we focused our analysis on DT days in June and January such that the average pre-urban and urban difference in $500 \mathrm{hPa}$ geopotential heights for the 4 grids closest to Phoenix were not statistically significant $(\mathrm{p}>0.05)$ through 2 -sample $t$-tests. We achieved this by culling the post-urban population in 2 ways, such that for all 4 of these grids (1) the range in geopotential heights was identical for both periods and (2) the number of days above and below the pre-urban mean geopotential height was identical for both periods. It is important to note that 2 more days were examined for the urban periods for both months. This was a result of 2 extra urban days which had $500 \mathrm{hPa}$ geopotential heights nearly equal to the pre-urban mean geopotential height.

In summary, we stratified our temperature data based on SSC2 DT conditions in June and January 


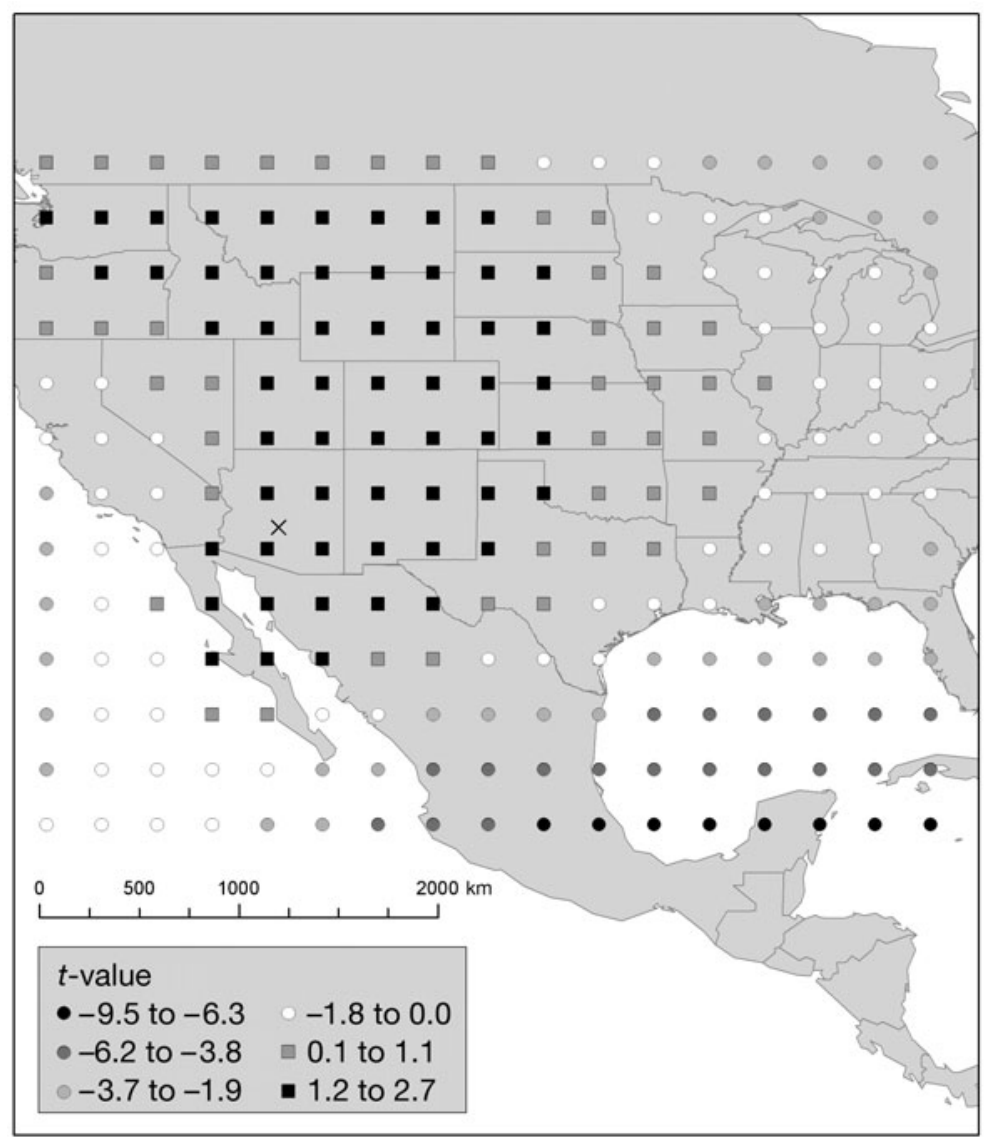

Fig. 4. Values (2-sample $t$-tests) for mean $500 \mathrm{hPa}$ geopotential height differences from pre-urban to urban periods across reanalysis grids covering the USA and part of Mexico. Squares (circles) indicate positive (negative) $t$-values and higher (lower) pre-urban mean geopotential heights. The degrees of freedom for these $t$-values are all greater than 218. $x$ : location of airport

such that the average $500 \mathrm{hPa}$ geopotential heights over Phoenix did not differ significantly between the pre-urban and urban periods. It should be noted that this requirement helps to validate the static climate assumption of the Lowry (1977) framework, as any large-scale climate change is controlled for through this requirement. Therefore, we examined $19 \%$ of the 620 possible January days and $45 \%$ of the 600 possible June days. For January and June, respectively, DM conditions were present on 40 and $24 \%$ of these days and the DT days not examined were present for 16 and $11 \%$ of these days.

\subsection{Analytical techniques}

We analyzed the pre-urban and urban differences for several elements of the diurnal temperature cycle: daily minimum and maximum temperatures and the hour of occurrence of the minimum and maximum temperatures. The significance of these differences was assessed through 2-sample $t$-tests; however, when error normality was not confirmed through the Ryan-Joiner test, we used the Kruskal-Wallis non-parametric test for equal medians to assess statistical significance. Maximum (minimum) temperature on a given day was determined as the highest (lowest) hourly temperature. For maximum temperatures, the only days considered were those that had no more than $1 \mathrm{~h}$ of missing data between 12:00 and 20:00 LST. For minimum temperatures, the only days considered were those that had no more than $1 \mathrm{~h}$ of missing data between 01:00 and 09:00 LST. Harmonic analysis (Svoma \& Balling 2009) was applied to the average hourly temperatures in order to further analyze differences in the timing of daily maximum and minimum temperatures. Hour 16 (15:00 to 16:00 LST) during the urban period in June had the highest percentage of missing data $(2.3 \%)$ and the average percentage of missing data for all hours considered in the present study was $0.13 \%$.

\section{RESULTS AND DISCUSSION}

Displayed in Fig. 5 are the average hourly temperatures for DT conditions in June and January for the pre-urban and urban periods. These plots suggest large increases in minimum temperature from the pre-urban to the urban period for both months. In addition, there appears to be an urban heat sink in maximum temperature present in January. More subtle pre-urban and urban differences are apparent in the hour of daily minimum temperature for both months. The 2-sample $t$-test results (Tables $2 \& 3$ ) for maximum and minimum temperatures and their hours of occurrence show numerous highly significant $(p<0.01)$ differences between pre-urban and urban periods.

The UHI had the greatest influence on minimum temperatures, as expected (Cayan \& Douglas 1984, Balling et al. 1990, Brazel et al. 2000, Fast et al. 2005). The average minimum temperatures were 4.4 and $2.4^{\circ} \mathrm{C}$ higher during the urban period for June and January, respectively (Table 2 ). These results are remarkably similar to the findings of Balling \& Brazel (1986), who noted a $4.5^{\circ} \mathrm{C}$ increase in summertime nocturnal temperatures from 1948 to 1984.

Brazel et al. (2000) analyzed urban-rural temperature differences during the month of May and found an urban heat sink in maximum temperatures for the 

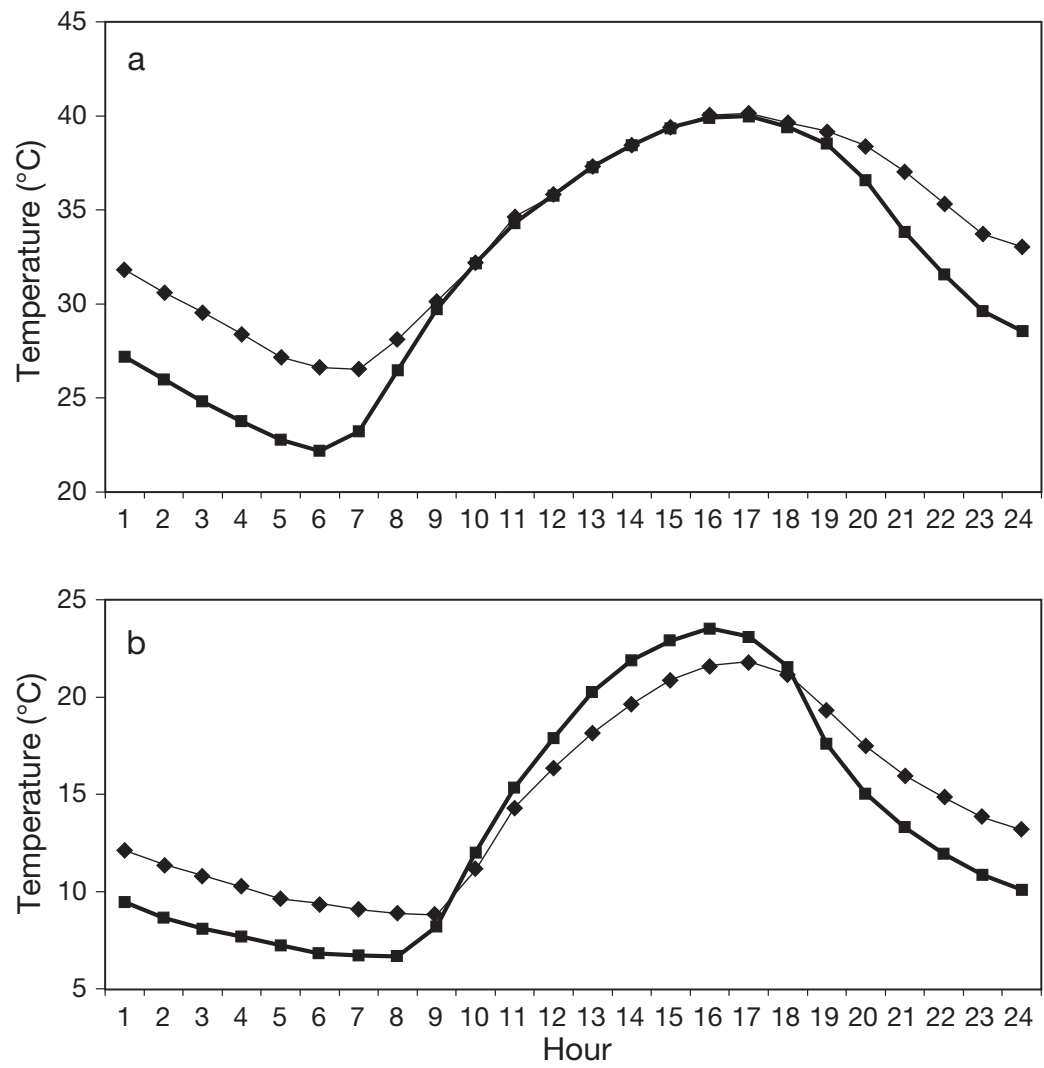

Fig. 5. Average hourly temperature $\left({ }^{\circ} \mathrm{C}\right)$ during dry tropical conditions in (a) June and (b) January for the pre-urban (thick black lines) and urban (thin black lines) periods. Hour 1 corresponds to 00:00 to 01:00 local standard time (LST), Hour 2 to 01:00 to 02:00 LST and so on urbanized areas in Phoenix which was attributed to higher humidity in the urban areas. Although there is no evidence that June maximum temperatures are influenced by the UHI during DT conditions (Table 2, Fig. 5), the maximum temperatures during DT conditions in January were significantly lower (by $1.5^{\circ} \mathrm{C}$ ) during the urban period (Table 2). The absence of an urban heat sink in June is likely due to powerful diurnal winds and mixing during the summer, as this is a desert environment with strong convection and significant horizontal wind flow during the day. This mixing likely serves to minimize the urban heat sink.

As expected, considering the reduced nocturnal cooling rates due to the greater thermal inertia of urbanization (Kidder \& Essenwanger 1995, Holmer et al. 2007), the average hour that the minimum temperature occurred was significantly later during the urban time period for both June and January (Table 3). In January, the minimum temperature occurred on average between 06:00 and 07:00 LST during the pre-urban period and between 07:00 and 08:00 LST during the urban period. In June, the minimum temperature occurred on average around 05:00 LST during the pre-urban period and between 05:00 and 06:00 LST during the urban period.

Table 2. Pre-urban and urban mean maximum and minimum temperatures $\left({ }^{\circ} \mathrm{C}\right)$ and sample sizes (in parentheses) and their differences with $p$-values (in parentheses)

\begin{tabular}{|c|c|c|c|c|c|c|}
\hline \multirow[t]{2}{*}{ Month } & \multicolumn{2}{|c|}{ Pre-urban } & \multicolumn{2}{|c|}{ Urban } & \multicolumn{2}{|c|}{ Difference } \\
\hline & Max. & Min. & Max. & Min. & Max. & Min. \\
\hline June & $40.6(134)$ & $21.9(134)$ & 40.7 (136) & $26.3(136)$ & $0.1(0.358)^{\mathrm{a}}$ & $4.4(0.001)$ \\
\hline January & $23.9(57)$ & $6.0(57)$ & $22.4(59)$ & $8.4(59)$ & $-1.5(0.001)$ & $2.4(<0.001)$ \\
\hline
\end{tabular}

Table 3. Pre-urban and urban hours of occurrence (h) of daily maximum and minimum temperatures and sample sizes (in parentheses) and their differences with p-values (in parentheses)

\begin{tabular}{|c|c|c|c|c|c|c|}
\hline \multirow[t]{2}{*}{ Month } & \multicolumn{2}{|c|}{ Pre-urban } & \multicolumn{2}{|c|}{ Urban } & \multicolumn{2}{|c|}{ Difference } \\
\hline & Max. & Min. & Max. & Min. & Max. & Min. \\
\hline June & $16.2(134)$ & $5.0(134)$ & $16.1(136)$ & $5.6(136)$ & $-0.1(0.338)$ & $0.6(<0.001)^{\mathrm{a}}$ \\
\hline January & $15.7(57)$ & $6.3(57)$ & $16.1(59)$ & 7.1 (59) & $0.4(0.013)$ & $0.8(<0.001)^{\mathrm{a}}$ \\
\hline
\end{tabular}

Table 4. First harmonic wave fitted to the average hourly temperatures for dry tropical conditions during June and January

\begin{tabular}{|c|c|c|c|c|c|c|c|c|}
\hline & \multicolumn{2}{|c|}{ Mean $\left({ }^{\circ} \mathrm{C}\right)$} & \multicolumn{2}{|c|}{ Amplitude $\left({ }^{\circ} \mathrm{C}\right)$} & \multicolumn{2}{|c|}{ Explained variance } & \multicolumn{2}{|c|}{ Time of minimum (LST) } \\
\hline & June & January & June & January & June & January & June & January \\
\hline Pre-urban & 31.7 & 13.6 & 8.5 & 8.0 & 0.98 & 0.91 & 3.8 & 3.6 \\
\hline Urban & 33.9 & 14.6 & 6.4 & 6.0 & 0.98 & 0.93 & 4.7 & 4.6 \\
\hline
\end{tabular}


Only in January did the average time of maximum temperature significantly differ between pre-urban and urban periods, with the maximum occurring on average between 15:00 and 16:00 LST during the preurban period and between 16:00 and 17:00 LST during the urban period. This later occurrence of maximum temperatures is again likely due to the greater thermal inertia present during the urban period.

The results above were represented well by the fit of the first harmonic wave to the average hourly temperature data (Table 4). The amplitude of the first harmonic was smaller during the urban period for both June and January. This suggests an increase in the minimum temperature during the urban period, considering that the daily mean temperature was higher during more recent years for both months (Table 4). In addition, the minimum of this fitted wave was earlier during the preurban periods for both months, again suggesting reduced cooling rates during the urban period. It should be noted that the minimum of the first harmonic is not indicative of the true average time of the daily minimum temperature because the first harmonic wave must have a maximum and a minimum separated by $12 \mathrm{~h}$, and this does not appear to be the case for the diurnal temperature cycle during DT conditions in June and January (Fig. 5). However, the direction of a shift in the phase angle of the first harmonic would be indicative of a shift in the same direction of the time of minimum or maximum temperatures.

\section{CONCLUSIONS}

Urban growth and airport development around the first-order weather station located at Sky Harbor International Airport in Phoenix, Arizona, greatly accelerated after 1948. To accurately quantify the influence of the resulting UHI on the diurnal cycle of air temperature, we employed the methods proposed by Lowry (1977) which are based on pre-urban and urban differences in temperature data stratified by synoptic weather type. We defined pre-urban (1948-1957) and urban (1998-2007) periods and examined hourly temperature data for DT conditions during June and January. The daily SSC2 developed by Sheridan (2002) was used to stratify the temperature data by DT conditions. Considering the significant urban bias present in the SSC2 during recent years, we also required that the average NCEP/NCAR reanalysis $500 \mathrm{hPa}$ geopotential heights not differ significantly between pre-urban and urban periods during the DT days considered for analysis.

The findings of the present study are consistent with previous literature concerning the UHI in Phoenix (Cayan \& Douglas 1984, Balling et al. 1990, Brazel et al. 2000, Fast et al. 2005). Minimum temperatures were more sensitive to the UHI than maximum temperatures, and in January there was evidence of a significant $(p<0.05)$ urban heat sink. The average UHI magnitude for minimum temperatures was highest in June $\left(4.4^{\circ} \mathrm{C}\right)$ and the average urban heat sink for maximum temperatures in January was $-1.5^{\circ} \mathrm{C}$. There is a lack of published articles concerning nocturnal cooling rates and the UHI in Phoenix. Our findings suggest reduced nocturnal cooling rates due to urbanization which are consistent with research conducted in other study areas (Kidder \& Essenwanger 1995, Holmer et al. 2007). Minimum temperatures occurred significantly later $(p<0.001)$ during the urban period. The first harmonic model of the diurnal temperature cycle was also indicative of reduced cooling rates due to urbanization in the Phoenix area.

There are numerous latent variables that must be accounted for with the methods used by many previous studies to determine the true magnitude of UHIs (Lowry 1977). The present study utilized a method capable of accurately measuring the true average heat island magnitude with assumptions about only a few latent variables (Lowry 1977). Thus the results found in the present study roughly represent the true UHI effect on the diurnal temperature cycle at Sky Harbor International Airport in Phoenix during DT conditions in June and January.

Acknowledgements. We thank S. Sheridan of Kent State Geography for providing data regarding the SSC2 development

\section{LITERATURE CITED}

Balling RC Jr, Brazel A (1986) Temporal analyses of summertime weather stress levels in Phoenix, Arizona. Arch Meteor Geophys Bioklim 36:331-341

Balling RC Jr, Cerveny RS (1987) Long-term associations between wind speeds and the urban heat island of Phoenix, Arizona. J Clim Appl Meteorol 26:712-716

Balling RC Jr, Skindlov JA, Phillips DH (1990) The impact of increasing summer mean temperatures on extreme maximum and minimum temperatures in Phoenix, Arizona. J Clim 3:1491-1494

Brazel A, Selover N, Vose R, Heisler G (2000) The tale of two climates: Baltimore and Phoenix urban LTER sites. Clim Res 15:123-135

Brazel A, Gober P, Lee SJ, Grossman-Clarke S, Zehnder J, Hedquist B, Comparri E (2007) Determinants of changes in the regional urban heat island in metropolitan Phoenix (Arizona, USA) between 1990 and 2004. Clim Res 33: $171-182$

> Cayan DR, Douglas AV (1984) Urban influences on surface temperatures in the southwestern United States during recent decades. J Clim Appl Meteorol 23:1520-1530

$>$ Fast JD, Torcolini JC, Redman R (2005) Pseudovertical temperature profiles and the urban heat island measured by a temperature datalogger network in Phoenix, Arizona. J Appl Meteorol 44:3-13 
Hansen J, Ruedy R, Glascoe J, Sato M (1999) GISS analysis of surface temperature change. J Geophys Res D 104: 30997-31022

> Hawkins TW, Brazel AJ, Stefanov WL, Bigler W, Saffell EM (2004) The role of rural variability in urban heat island determination for Phoenix, Arizona. J Appl Meteorol 43:476-486

Holmer B, Thorsson S, Eliasson I (2007) Cooling rates, sky view factors and the development of intra-urban air temperature differences. Geogr Ann A 89:237-248

Kalkstein LS, Nichols MC, Barthel CD, Greene JS (1996) A new spatial synoptic classification: application to air-mass analysis. Int J Clim 16:983-1004

Kalkstein LS, Sheridan SC, Graybeal DY (1998) A determination of character and frequency changes in air masses

Editorial responsibility: Helmut Mayer,

Freiburg, Germany using a spatial synoptic classification. Int J Clim 18: 1223-1236

Kidder SQ, Essenwanger OM (1995) The effect of clouds and wind on the difference in nocturnal cooling rates between urban and rural areas. J Appl Meteorol 34:2440-2448

Lowry WP (1977) Empirical estimation of urban effects on climate: a problem analysis. J Appl Meteorol 16:129-135

Lowry WP (1998) Urban effects on precipitation amount. Prog Phys Geogr 22:477-520

Sheridan SC (2002) The redevelopment of a weather-type classification scheme for North America. Int $\mathrm{J}$ Clim 22:51-68

Svoma BM, Balling RC Jr (2009) An anthropogenic signal in Phoenix, Arizona winter precipitation. Theor Appl Climatol 98:315-321

Submitted: May 28, 2009; Accepted: August 31, 2009

Proofs received from author(s): January 17, 2010 